\title{
Resveratrol Alleviates Ethanol-Induced Hormonal and Metabolic Disturbances in the Rat
}

\author{
K. SZKUDELSKA ${ }^{1}$, M. DENIZIAK ${ }^{2}$, P. ROŚ ${ }^{2}$, K. GWÓŹDŹ ${ }^{1}$, T. SZKUDELSKI ${ }^{1}$ \\ ${ }^{1}$ Department of Animal Physiology and Biochemistry, Poznan University of Life Sciences, Poznan, \\ Poland, ${ }^{2}$ Department of Biochemistry and Cell Biology, University of Rzeszow, Rzeszów, Poland
}

Received February 29, 2016

Accepted June 3, 2016

On-line October 26, 2016

\section{Summary}

Resveratrol is a polyphenol found in different plant species and having numerous health-promoting properties in animals and humans. However, its protective action against deleterious effects of ethanol is poorly elucidated. In the present study, the influence of resveratrol $(10 \mathrm{mg} / \mathrm{kg} /$ day) on some hormones and metabolic parameters was determined in rats ingesting $10 \%$ ethanol solution for two weeks. Blood levels of insulin, glucagon and adiponectin were affected by ethanol, however, resveratrol partially ameliorated these changes. Moreover, in ethanol drinking rats, liver lipid accumulation was increased, whereas resveratrol was capable of reducing liver lipid content, probably due to decrease in fatty acid synthesis. Resveratrol decreased also blood levels of triglycerides and free fatty acids and reduced y-glutamyl transferase activity in animals ingesting ethanol. These results show that resveratrol, already at low dose, alleviates hormonal and metabolic changes induced by ethanol in the rat and may be useful in preventing and treating some consequences of alcohol consumption.
\end{abstract}

\section{Key words}

Resveratrol • Ethanol • Hormones • Metabolism • Rats

\section{Corresponding author}

K. Szkudelska, Department of Animal Physiology and Biochemistry, Poznan University of Life Sciences, Wolynska 35, 60-637 Poznan, Poland. Fax: +48 61 8487197. E-mail: katewa@poczta.onet.eu

\section{Introduction}

Resveratrol (3,5,4'-trihydroxystilbene) is a polyphenol present in different plant species, including grapes, berries and peanuts. It is also one of the bioactive compounds found in red wine and has been proposed to be responsible for the "French paradox", i.e. low mortality due to coronary heart disease as a result of moderate consumption of red wine (Kopp 1998). Recently, resveratrol is of great interest because of its pleiotropic, health-promoting properties that have been documented not only in animals but also in humans. Rodent and human studies show that resveratrol exerts, among others, cardio-protective (Zordoky et al. 2015), anti-cancer (Singh et al. 2015), anti-diabetic (Szkudelski and Szkudelska 2015), anti-inflammatory (Poulsen et al. 2015), anti-obesity (Szkudelska and Szkudelski 2010, de Ligt et al. 2015), neuro-protective (Bastianetto et al. 2015) and anti-oxidative (Farghali et al. 2013) action.

Among various effects of resveratrol, much attention has been paid to its ameliorative potential in metabolic disorders. It is known that resveratrol mimics lower energy intake, increases survival, improves motor function as well as other parameters related to longer lifespan (Baur et al. 2006, Bhullar and Hubbard 2015). Results of rodent studies also point to the effectiveness of this compound in diet-induced obesity and insulin resistance. In animals fed a high-calorie diet, resveratrol is capable of improving insulin action, reducing body weight and adiposity (de Ligt et al. 2015). Consistent with these data, resveratrol was also found to directly affect cells of white adipose tissue. It was demonstrated that adipocyte exposure to resveratrol decreases lipogenesis and enhances lipolysis leading to lower lipid accumulation in fat cells (Szkudelska et al. 2009, Szkudelska and Szkudelski 2010). Apart from adipose tissue, resveratrol induces also a wide variety of effects in 
skeletal muscle and liver improving their function under various pathological conditions. In skeletal muscle, resveratrol, among others, promotes mitochondrial biogenesis and reduces intramuscular lipid content and thereby improves insulin action (de Ligt et al. 2015). Hepatoprotective properties of this compound are mainly associated with decreased liver lipid accumulation and amelioration of both oxidative stress and inflammation (Bishayee et al. 2010, de Ligt et al. 2015).

The beneficial action of resveratrol is associated with changes in the activities of numerous intracellular enzymes and signaling molecules. Among its molecular targets, silent information regulator 1 (SIRT1) and AMP-activated protein kinase (AMPK) are thought to play a crucial role (Farghali et al. 2013, Kulkarni and Cantó 2015).

It is known that resveratrol may also ameliorate some consequences of ethanol ingestion. In humans, alcohol abuse is associated with numerous abnormalities in the whole organism, such as metabolic disorders, increased risks of cancer, liver injury, cardiovascular diseases, neuropathies, myopathies and also with increased mortality (Sun et al. 2014, Luo 2014, Fernandez-Solà et al. 2007, Ceni et al. 2014). Ethanol consumption is also accompanied by oxidative stress and inflammation in different tissues (Sun et al. 2001, Setshedi et al. 2010, Radek et al. 2009, Kawaratani et al. 2013). Rodent studies indicate that resveratrol decreases lipid peroxidation in some tissues (Kasdallah-Grissa et al. 2006) and reduces ethanol-induced oxidative stress in the liver (Kasdallah-Grissa et al. 2007, Das et al. 2010). Oliva et al. (2008) also revealed that ethanol up-regulates Sirt1 and PGC1 $\alpha$ in the rat liver and that these effects may be prevented by resveratrol. These results are in contrast to the notion that resveratrol activates Sirt1 in mammalian tissues and this is associated with beneficial effects of this compound (Kulkarni and Cantó 2015). On the other hand, in the experiment of Oliva et al. (2008), effects of resveratrol on Sirt1 were not accompanied by reduction in liver damage, which indicates that the link between resveratrol and Sirt1 is dysregulated by ethanol.

However, in spite of these data, the potential of resveratrol in preventing ethanol-induced hormonal and metabolic disturbances is still poorly elucidated. The aim of the present study was to determine whether resveratrol is effective in alleviating these abnormalities in ethanol consuming rats.

\section{Materials and Methods}

\section{Reagents and analytical kits}

Trans-resveratrol, ethanol, dimethyl sulfoxide (DMSO), glucose oxidase, peroxidase, dianisidine and reagents used to determine fatty acids, triglycerides, lactate, reagents for Folch extraction, vanillin, $\mathrm{KOH}$, amyloglucosidase, reagents used for preparation of buffer to liver lysis, reagents to Bradford method were provided from Sigma-Aldrich (St. Louis, MO, USA). Rabbit primary antibodies against insulin receptor were purchased from Santa Cruz Biotechnology (Dallas, TX, USA), and rabbit primary antibodies against pAMPK, pACC and $\beta$-actin were from Cell Signalling Technology, Inc. (Danvers, MA, USA) Polyvinylidene difluoride membranes were bought from Roche (Basel, Switzerland). SuperSignal ${ }^{\circledR} \quad$ West Pico Chemiluminescent Substrate and CL-XPosure ${ }^{\mathrm{TM}}$ Film were purchased from Thermo Scientific. Peroxidaseconjugated anti-rabbit antibody was purchased from Jackson ImmunoResearch Laboratories (West Grove, PA, USA). Kits for measurements of insulin, glucagon and adiponectin concentrations were from EMD Millipore (Billerica, MA, USA), and for $\gamma$-glutamyl transferase from Pointe Scientific (Canton, MI, USA).

\section{Animals and treatment}

In the experiment, 32 male Wistar rats obtained from Brwinow (Poland) were used. Animals were maintained in cages in an air conditioned room with a constant temperature of $21 \pm 1{ }^{\circ} \mathrm{C}$ and $12 / 12$ dark/light cycle. Rats were fed ad libitum a standard laboratory diet (Labofeed, Motycz, Poland). Prior to the experiment, animals were divided into four groups. Animals from the first group drank water and received the mixture of DMSO: $\mathrm{H}_{2} \mathrm{O}$. Rats from the second group drank ethanol solution and received DMSO: $\mathrm{H}_{2} \mathrm{O}$. In the third group, animals drank water and received DMSO $: \mathrm{H}_{2} \mathrm{O}$ with resveratrol. In the last group, rats drank ethanol solution and received DMSO : $\mathrm{H}_{2} \mathrm{O}$ with resveratrol. The mixture DMSO: $\mathrm{H}_{2} \mathrm{O}(1: 4)$ with or without resveratrol was given intragastrically once a day $(0.5 \mathrm{ml} / 100 \mathrm{~g}$ body weight). Ethanol was prepared as $10 \%$ solution and was the only drinking fluid. The dose of resveratrol was $10 \mathrm{mg}$ per $\mathrm{kg}$ body weight. After 14 days of the experiment, rats were decapitated and blood serum, livers and muscles (musculus biceps femoris) were sampled and stored $\left(-80^{\circ} \mathrm{C}\right)$ until analysis. The experiment was performed according to the rules and protocols accepted by the 
Local Ethical Commission for Investigation on Animals.

\section{Blood hormone levels and metabolic parameters}

All parameters, except fasting blood glucose, were measured in non-fasted rats. Blood levels of insulin, glucagon and adiponectin were determined radioimmunologically using kits specific for rat hormones. Blood glucose was measured by the enzymatic method with glucose oxidase and dianisidine (Bergmeyer and Bernt 1974). Free fatty acids and triglycerides were determined colorimetrically (Duncombe 1964, Foster and Dunn 1973). Lactate was determined by the measure of $\mathrm{NADH}$ formed from $\mathrm{NAD}^{+}$in the presence of lactate dehydrogenase (Everse 1975). The activity of $\gamma$-glutamyl transferase in the blood was measured using a kit and according to manufacturer instruction.

Fasting blood glucose was determined after 10 days of the experiment. For this purpose, rats were fasted overnight, blood samples were taken from the tail vein and glucose was measured using a glucometer (HemoCue Glucose 201, Angelholm, Sweden).

\section{Liver and muscle metabolic parameters}

Liver lipids were extracted by the method of Folch et al. (1975). Total lipids were determined by the method with vanillin, whereas liver triglycerides were determined similarly as in blood. To determine liver and muscle glycogen, tissue samples were hydrolysed in $30 \% \mathrm{KOH}$, then glycogen was hydrolysed with amyloglucosidase as described previously (Szkudelski 2005) and determined similarly as blood glucose.

\section{Protein expression of $p A M P K, \quad p A C C$ and insulin receptor}

Protein expression was determined in the liver by Western blot. For this purpose, total protein extracts of rat liver were prepared according to Jiang et al. (2004) with the following modifications. Rat liver tissue ( $\approx 100 \mathrm{mg}$ ) was suspended in $1 \mathrm{ml}$ of cold lysis buffer, homogenized on ice for $1 \mathrm{~min}$, sonicated $(50 \mathrm{~W}, 3 \times 10 \mathrm{~s})$ and centrifuged (14000 rpm, $30 \mathrm{~min})$. Protein concentration in recovered supernatants was assessed by Bradford method and extracts obtained from individuals belonging to each group were pooled. Protein samples (10 $\mu \mathrm{g} /$ lane) were separated by SDS-polyacrylamide gel electrophoresis and transferred (Mini-Protein Tetra Cell and Mini Trans-Blot systems, Bio-Rad) to polyvinylidene difluoride membranes. Blots were washed, blocked with
$5 \%$ skim milk and incubated overnight at $4{ }^{\circ} \mathrm{C}$ with rabbit primary antibodies against insulin receptor $(1: 1,600)$, pAMPK $(1: 2,000)$, pACC $(1: 5,000)$ or $\beta$-actin $(1: 10,000)$. After transfer to room temperature and wash, membranes were incubated for $1 \mathrm{~h}$ with peroxidaseconjugated anti-rabbit antibody (1:20,000). Immunoreactive bands were revealed using SuperSignal ${ }^{\circledR}$ West Pico Chemiluminescent Substrate and X-ray film. The protein signal was analyzed by densitometry using Azure c300 Imaging System and AzureSpot v. 13.1 software (Azure Biosystems).

\section{Statistical analysis}

The obtained results are expressed as means \pm SEM of 8 rats and were evaluated statistically using analysis of variance and Duncan's multiple-range test. Differences were considered significant at $\mathrm{P}<0.05$.

\section{Results}

\section{Effect of resveratrol on blood hormone levels}

The present study demonstrated that ethanol ingestion for two weeks significantly reduced body weight gain and evoked hormonal changes in rats. Resveratrol did not affect body weight gain; however, the tested compound ameliorated hormonal changes in ethanol consuming rats. It was demonstrated that ethanol ingestion reduced blood insulin levels by half compared with control animals. This effect was, however, significantly alleviated by resveratrol. Resveratrol did not induce any significant changes in blood insulin concentrations in control rats that were not treated with ethanol (Fig 1). Moreover, blood glucagon levels were found to be increased by ethanol, whereas resveratrol attenuated this effect. Resveratrol failed to affect blood glucagon concentrations in control animals (Fig. 1). These hormonal alterations were accompanied by significant alterations in insulin/glucagon ratio. Ethanol significantly abated this ratio; however, this effect was partially prevented by resveratrol (Table 1).

Apart from pancreatic hormones, blood adiponectin levels were also determined. In the present study, ethanol ingestion evoked significant increase in blood adiponectin concentrations. The effect of ethanol on blood adiponectin levels was attenuated by resveratrol ingestion. Similarly to the pancreatic hormones, resveratrol was demonstrated to be without any influence on blood adiponectin in control rats (Fig. 1). 

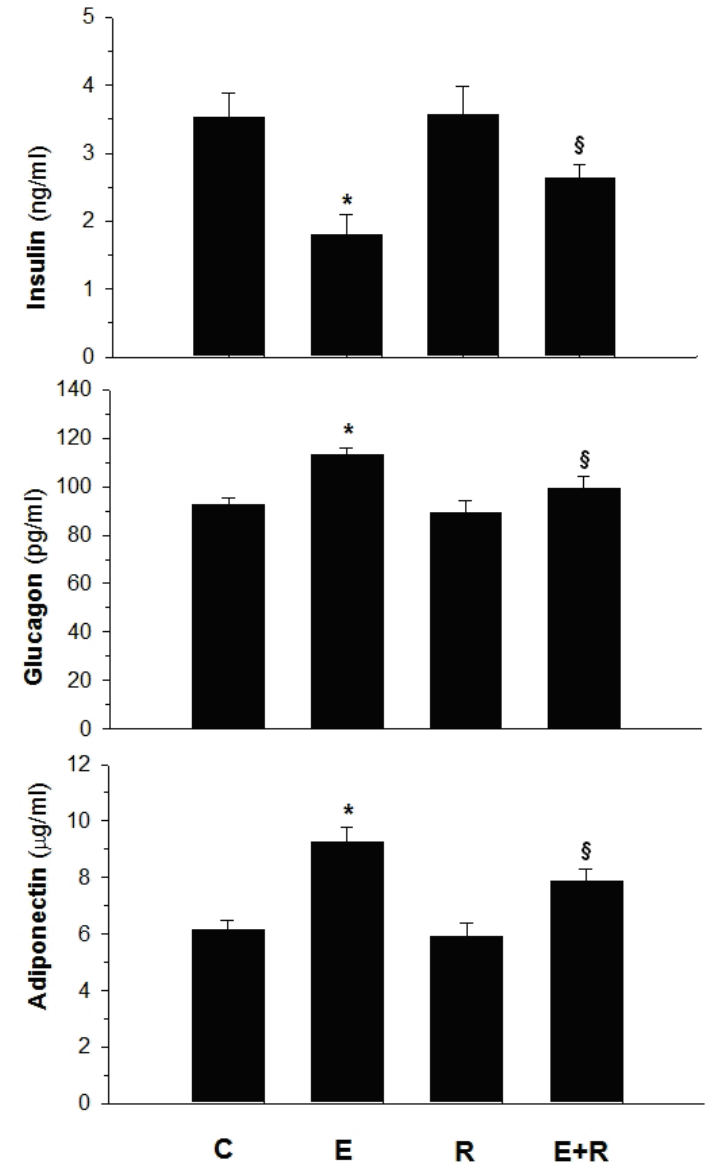

Fig. 1. Effect of resveratrol on blood insulin, glucagon and adiponectin levels in control and ethanol-treated rats. Values represent means $\pm \operatorname{SEM}(n=8)$. $C-$ Control, $E-$ Ethanol, $R-$ Resveratrol, $*-\mathrm{P}<0.05$ vs. $\mathrm{C}$ and $\mathrm{E}+\mathrm{R},{ }^{\S}-\mathrm{P}<0.05$ vs. $\mathrm{C}$ and $\mathrm{E}$.

\section{Effect of resveratrol on metabolic parameters}

It was demonstrated that blood glucose levels in non-fasted rats are not significantly affected neither by ethanol nor by resveratrol. However, concentrations of fasting blood glucose were influenced by ethanol alone and by ethanol with resveratrol. Ethanol significantly reduced fasting blood glucose levels and this effect was deepened in the presence of resveratrol (Table 1). Concentrations of lactate in the blood were unchanged in rats receiving ethanol and/or resveratrol (Table 1). However, significant changes in lipid metabolism were shown. It was found that ethanol increased blood levels of free fatty acids, whereas resveratrol restored them to the values observed in control rats (Fig. 2). Similar changes were observed in the case of blood levels of triglycerides, i.e. increase in ethanol-consuming rats and normalization by resveratrol (Fig. 2).

The present study demonstrated that ingestion of $10 \%$ ethanol solution for two weeks resulted in significant increase in liver lipid accumulation. Ethanol induced increase in total lipids and triglycerides in the liver. Importantly, in rats that were given ethanol and resveratrol, this effect was markedly reduced. It was also demonstrated that resveratrol alone failed to influence liver lipid content in control rats (Fig. 3).

In our study, both ethanol and resveratrol did not significantly change the liver and muscle glycogen stores (Table 1).

To provide more data on the hepatoprotective effects of resveratrol, $\gamma$-glutamyl transferase activity in blood serum of rats was also determined. The activity of this enzyme was increased by ethanol, whereas resveratrol ameliorated this effect (Table 1).

Table 1. Effect of resveratrol on selected parameters in control and ethanol-treated rats.

\begin{tabular}{|c|c|c|c|c|}
\hline Parameter & $\begin{array}{c}\text { Water* } \\
\text { Vehicle** }\end{array}$ & $\begin{array}{c}10 \% \text { Ethanol* } \\
\text { Vehicle** }\end{array}$ & $\begin{array}{l}\text { Water* } \\
\text { RSV*** }\end{array}$ & $\begin{array}{c}10 \% \text { Ethanol } * \\
\text { RSV }^{* *}\end{array}$ \\
\hline Initial body weight ( $g$ ) & $161 \pm 4$ & $158 \pm 3$ & $164 \pm 3$ & $156 \pm 3$ \\
\hline Final body weight (g) & $276 \pm 5^{\mathrm{A}}$ & $227 \pm 5^{\mathrm{B}}$ & $271 \pm 6^{\mathrm{A}}$ & $227 \pm 6^{\mathrm{B}}$ \\
\hline Body weight gain (g/day) & $8.2 \pm 0.2^{\mathrm{A}}$ & $4.9 \pm 0.3^{\mathrm{B}}$ & $7.6 \pm 0.2^{\mathrm{A}}$ & $5.1 \pm 0.4^{\mathrm{B}}$ \\
\hline Fasting glucose (mM) & $4.64 \pm 0.1^{\mathrm{A}}$ & $3.84 \pm 0.2^{\mathrm{B}}$ & $4.65 \pm 0.2^{\mathrm{A}}$ & $3.40 \pm 0.1^{\mathrm{C}}$ \\
\hline Non-fasting glucose (mM) & $6.41 \pm 0.3$ & $5.82 \pm 0.4$ & $7.40 \pm 0.7$ & $6.93 \pm 0.6$ \\
\hline Lactate $(m M)$ & $5.00 \pm 0.3$ & $5.67 \pm 0.4$ & $5.51 \pm 0.3$ & $5.52 \pm 0.4$ \\
\hline Insulin/glucagon ratio $\left(x 10^{-2}\right)$ & $3.81 \pm 0.1^{\mathrm{A}}$ & $1.58 \pm 0.2^{\mathrm{B}}$ & $3.99 \pm 0.2^{\mathrm{A}}$ & $2.65 \pm 0.3^{\mathrm{C}}$ \\
\hline$\gamma$-Glutamyl transferase $(\mu \mathrm{U} / \mathrm{ml})$ & $5.38 \pm 0.3^{\mathrm{A}}$ & $7.18 \pm 0.5^{\mathrm{B}}$ & $5.53 \pm 0.4^{\mathrm{A}}$ & $6.16 \pm 0.4^{\mathrm{A}}$ \\
\hline Liver glycogen $(m g / g)$ & $56.6 \pm 4.1$ & $66.7 \pm 5.4$ & $64.8 \pm 5.9$ & $63.3 \pm 4.9$ \\
\hline Muscle glycogen ( $\mathrm{mg} / \mathrm{g})$ & $5.7 \pm 1.4$ & $5.2 \pm 0.8$ & $5.2 \pm 0.9$ & $6.5 \pm 1.4$ \\
\hline
\end{tabular}

Values represent the mean $\pm \operatorname{SEM}(n=8)$. Means with different letter superscripts differ statistically $(P<0.05)$. - drinking fluid, $* *$ - intragastric administration of vehicle (DMSO: $\mathrm{H}_{2} \mathrm{O}, 1: 4$ ) or resveratrol (RSV, $10 \mathrm{mg} / \mathrm{kg} /$ day, dissolved in vehicle). 

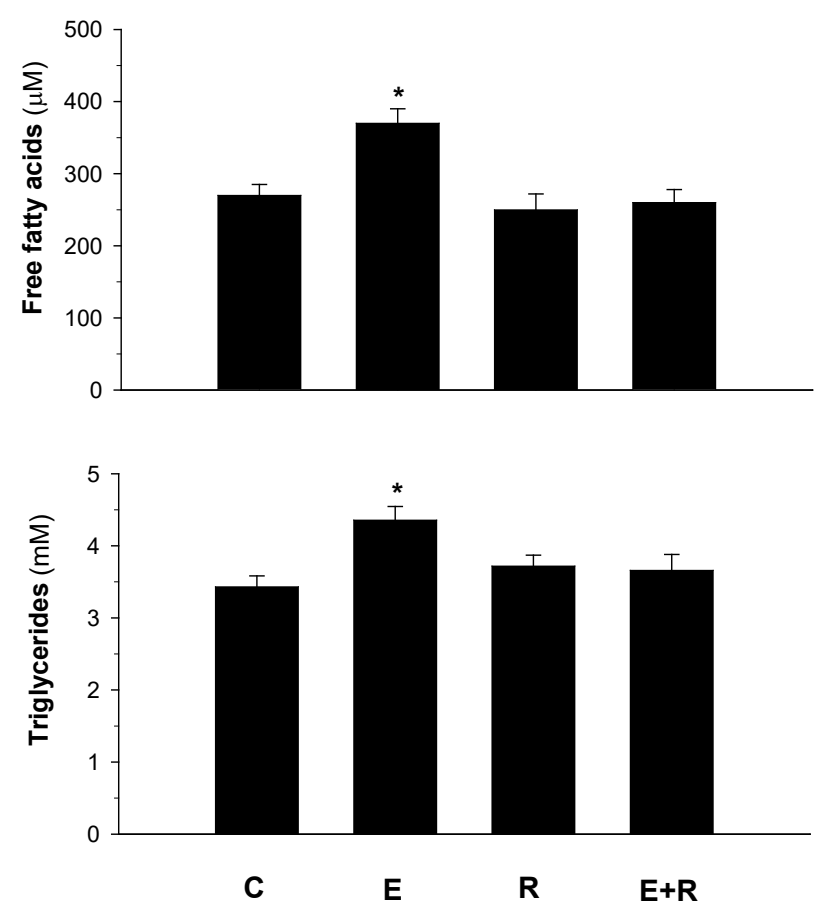

Fig. 2. Effect of resveratrol on blood free fatty acid and triglyceride levels in control and ethanol-treated rats. Values represent means \pm SEM $(n=8)$. C - Control, E - Ethanol, $\mathrm{R}-$ Resveratrol, $*-\mathrm{P}<0.05$ vs. $\mathrm{C}$ and $\mathrm{E}+\mathrm{R}$.

Effect of resveratrol on protein expression of pAMPK, pACC and insulin receptor

In the present study, pAMPK expression in the liver was slightly reduced by ethanol compared with control animals, and this effect was suppressed by resveratrol (Fig. 4). It was also demonstrated that in the rats treated with ethanol or resveratrol, pACC expression in the liver tissue was increased compared with control rats. This effect was additionally potentiated in the rats treated with both resveratrol and ethanol (Fig. 4). Compared with the control rats, insulin receptor expression in the liver was unchanged neither by ethanol nor by resveratrol (Fig. 4).

\section{Discussion}

Resveratrol, a plant-derived diphenolic compound, is known to exert numerous beneficial effects in the organism. Results of the present study show the capacity of resveratrol to alleviate hormonal and metabolic changes induced by ethanol in the rat.

It was demonstrated that blood insulin levels were significantly reduced by ethanol. Similar effect was previously found in rats ingesting $10 \%$ ethanol solution for ten days (Szkudelski and Kandulska 1999) or for two
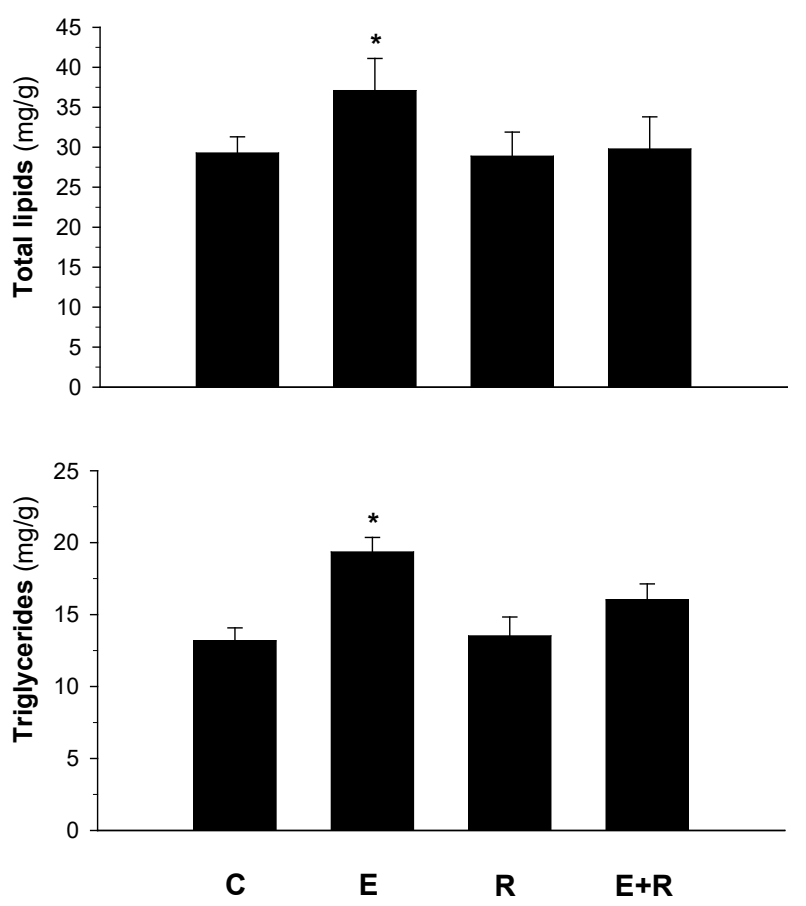

Fig. 3. Effect of resveratrol on liver total lipids and triglycerides in control and ethanol-treated rats. Values represent means \pm SEM $(n=8)$. C - Control, E - Ethanol, R - Resveratrol, $*-\mathrm{P}<0.05$ vs. $\mathrm{C}$ and $\mathrm{E}+\mathrm{R}$.

weeks (Szkudelski et al. 2004, Szkudelska et al. 2007). Importantly, our present study revealed for the first time that the unfavourable effect of ethanol on blood insulin levels is markedly alleviated by resveratrol. Taking into account the physiological relevance of insulin, this seems to be one of the most significant findings. Ethanolinduced decrease in blood insulin levels is known to result from morphological, structural and functional defects within pancreatic islets (Singh et al. 1986, Koko et al. 1995, Zhao et al. 2009). Therefore, the rise in insulinemia caused by resveratrol in ethanol-consuming rats clearly indicates the protective action of the tested stilbene on the endocrine pancreas. This is in parallel with data showing the protective action of resveratrol on the pancreas in rats with streptozotocin-nicotinamideinduced diabetes (Palsamy and Subramanian 2010), in rodents on a high-fat diet (Zhang et al. 2012, Kong et al. 2015), with carboxymethyllysine-induced pancreas dysfunction (Lee et al. 2013) and in $\mathrm{db} / \mathrm{db}$ mice (Lee et al. 2012). In all these cases, resveratrol was effective in spite of different mechanisms underlying dysfunction of the insulin-secreting cells. Our results additionally show that resveratrol is also capable of exerting the protective action against functional defects induced by ethanol in $\beta$-cells of rats. It should be, however, mentioned that the 
positive effect of resveratrol on blood insulin levels in rats ingesting ethanol was insufficient to prevent a decrease in body weight gain in these animals. It was previously demonstrated that ethanol may reduce body

A

IR

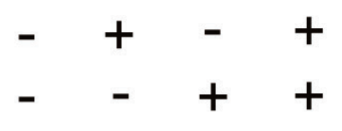

ethanol

resveratrol

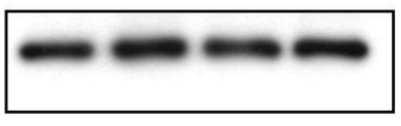

pAMPK

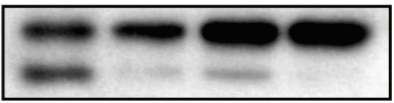

pACC

$\beta$-actin
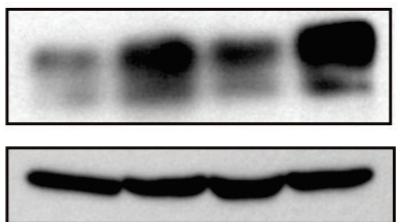

weight gain in rats in spite of unchanged concentrations of blood insulin (Pravdova et al. 2009). These results indicate that the link between body weight gain and blood insulin levels is dysregulated by ethanol ingestion.

Fig. 4. Effect of resveratrol on protein expression of insulin receptor (IR), PAMPK and PACC and in the liver of control and ethanol-treated rats. Western blot signals representative for IR, PAMPK and PACC protein levels, $\beta$-actin was used as the internal loading control, each protein was detected in pooled total protein samples isolated from rat livers $(n=8)(\mathbf{A})$. Protein expression relative to untreated control (B), quantified by densitometry, for rats treated with ethanol $(E)$, resveratrol $(R)$ or ethanol and resveratrol $(E+R)$.

B

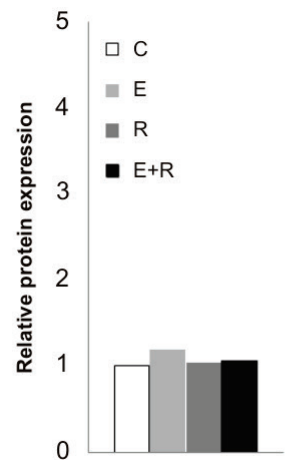

IR

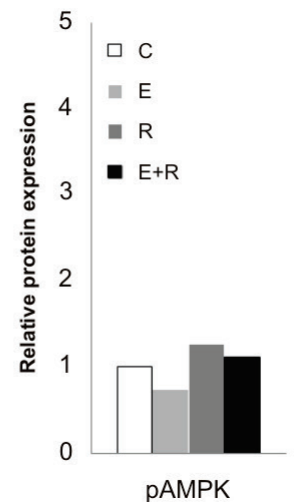

PAMPK

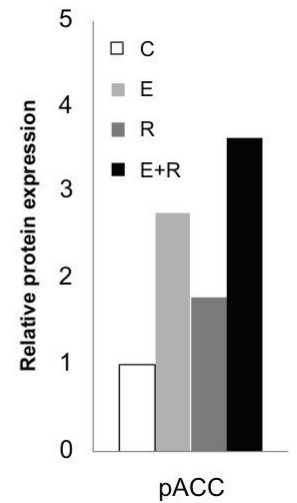

glucose levels (Sumida et al. 2007), whereas hypoglycemic effect of resveratrol in the combination with ethanol seems to result from increased glucose transport into tissues, especially skeletal muscle (Breen et al. 2008, Deng et al. 2008). Hypoglycemia was, however, not induced by resveratrol alone, due to the compensatory effect of hepatic gluconeogenesis.

In the previous studies showing beneficial effects of resveratrol in ethanol consuming rodents, blood insulin and glucagon levels were not taken into account glucose uptake. Ethanol is known to inhibit hepatic 
and resveratrol was proposed to exert direct influence on liver and on some other tissues (Kasdallah-Grissa et al. 2006, Oliva et al. 2008, Ajmo et al. 2008). Our present study revealed that, apart from these effects, resveratrol alleviated hormonal abnormalities in ethanol-consuming rats, namely increased blood insulin and decreased blood glucagon levels. The latter effect is probably due to the inhibitory action of insulin secreted by $\beta$-cells on the adjacent $\alpha$-cells within the pancreatic islets (Schatz and Kullek 1980). Resveratrol-induced improvement in pancreatic hormone levels lead to the increase in the insulin/glucagon ratio and these changes undoubtedly contributed to the partial normalization of metabolic parameters in ethanol-consuming rats. This is particularly seen in the case of blood levels of free fatty acids, triglycerides and liver lipids.

It is known that insulin action on target tissues is preceded by its binding to insulin receptor. Under some pathological conditions, the number of these receptors may be affected, leading to disturbed insulin signaling. However, our results demonstrated that neither ethanol nor resveratrol induced any significant changes in insulin receptor protein expression in the liver.

Increased liver lipid accumulation is one of the most typical harmful implications of ethanol ingestion. Prolonged ethanol consumption leads to development of fatty liver, mitochondrial dysfunction, ceramide accumulation and is associated with liver cirrhosis (Ceni et al. 2014, Tong et al. 2014). Since fatty liver is known to be reversible, numerous natural compounds are continuously being tested in the context of their capability to reduce ethanol-induced liver lipid accumulation (Ding et al. 2012). In the present study, total lipid content and triglyceride content in the liver of ethanol-consuming rats was augmented compared with control animals. However, these unfavourable changes appeared to be prevented by resveratrol. The protective action of resveratrol against increased liver lipid accumulation has been previously shown in rats fed a high-fat diet (Shang et al. 2008, de Ligt et al. 2015) and also in ethanol-treated mice (Ajmo et al. 2008). In the latter case, resveratrol-induced decrease in liver lipids was due to both reduced lipid synthesis and increased fatty acid oxidation and was accompanied by up-regulation of a SIRT1-AMPK signalling pathway. However, compared with our present study, doses of resveratrol required to induce these changes were high since mice were given 200 or $400 \mathrm{mg}$ of resveratrol per $\mathrm{kg}$ body weight (Ajmo et al. 2008).
The role of AMPK, and some other enzymes that are regulated by this kinase, in alleviating ethanolinduced liver lipid accumulation is controversial since ethanol was demonstrated to augment (Nammi and Roufogalis 2013, Zeng et al. 2014) or reduce AMPK phosphorylation (Liu et al. 2014, Jiang et al. 2015) and activity (García-Villafranca et al. 2008) in the rodent liver. In general, AMPK is activated by both phosphorylation and a rise in AMP/ATP ratio, and activation of this enzyme in response to low intracellular energy levels shifts metabolic pathways towards increased ATP generation with a concomitant restriction of ATP-consuming processes (Hardie 2015). It is known that pAMPK phosphorylates downstream targets, including a mitochondrial enzyme acetyl-CoA carboxylase (ACC). Phosphorylation of ACC by pAMPK is at an inhibitory site and thereby is linked to decreased conversion of acetyl-CoA to malonyl-CoA, finally promoting $\beta$-oxidation of long-chain fatty acids (Schreurs et al. 2009) and may lead to reduced lipid accumulation in tissues. However, the link between AMPK, ACC and liver lipid accumulation may by disturbed by ethanol. Zeng et al. (2014) demonstrated that ethanol increases liver lipid accumulation in mice and this effect is accompanied by an increase in pAMPK and reduced protein levels of pACC and fatty acid synthase. On the other hand, mRNA of ACC may be increased in the liver of ethanol-treated rodents (Liu et al. 2014, Jiang et al. 2015). In our present study, ethanol slightly reduced pAMPK protein expression in the liver compared with control animals, whereas resveratrol increased pAMPK in both control and ethanol-consuming rats. Protein expression of pACC in the liver was unexpectedly increased by both resveratrol and ethanol compared with control rats. Since both these compounds induced increase in pACC, the protective effect of resveratrol on ethanol-induced liver lipid accumulation seems to be pACC-independent. These results suggest that resveratrol may reduce liver lipid accumulation in ethanol-treated rats via the decrease in fatty acid synthesis at steps following formation of malonyl-CoA. This is supported by data showing that resveratrol inhibited fatty acid synthase in the liver of mice fed a high-fat diet (Cho et al. 2012). It should be emphasized that in the current study, this effect was induced by $10 \mathrm{mg}$ resveratrol. This is of importance since the mechanism of resveratrol action may differ depending on its dose (Price et al. 2012, Gómez-Zorita et al. 2013).

Apart from decrease in liver lipids, the beneficial 
effect of resveratrol in ethanol-consuming rats revealed also by reduced activity of $\gamma$-glutamyl transferase in the blood, which also points at the hepatoprotective action of the tested compound.

It is known that endocrine function of white adipose tissue is affected by ethanol. Adiponectin is one of the adipokines secreted by this tissue. Its disturbed secretion and action is associated with ethanol-induced liver diseases (Rogers et al. 2008). Effects of ethanol on blood adiponectin levels may differ depending on experimental conditions (Ajmo et al. 2008, Pravdova et al. 2008, Tian et al. 2014). Chronic ethanol ingestion is usually associated with reduced adipose tissue mass and diminished blood adiponectin levels (Yu et al. 2010, Tian et al. 2014, Zhu et al. 2014, Jiang et al. 2015, Kema et al. 2015). In our present study, blood adiponectin concentrations were increased after two weeks of ethanol ingestion, whereas resveratrol slightly reduced this effect. This indicates that resveratrol is capable of ameliorating ethanol-induced changes not only in the endocrine pancreas and liver, but also in adipose tissue.

The influence of resveratrol on blood adiponectin levels in ethanol-ingesting rats was accompanied by beneficial changes in concentrations of blood insulin and glucagon these animals. All these hormones have a great importance in the regulation of fat tissue accumulation. However, blood levels of these hormones did not returned to the control values. It seems that this may be the reason that resveratrol action appeared to be insufficient to improve body weight gain. Moreover, Pravdova et al. (2008) demonstrated that ethanol intake ( $6 \%$, for 28 days) reduced body weight gain and adiposity in the rat, however, adiponectin expression and blood adiponectin levels were increased. Similarly to adiponectin, it was also demonstrated that ethanol ingestion may increase blood leptin levels in the rat in spite of reduced body weight gain (Pravdova et al. 2009, Szkudelski et al. 2004).

In conclusion, the present study demonstrated that resveratrol is capable of inducing beneficial effects in ethanol-consuming rats. This compound was found to diminish liver lipid accumulation and significantly alleviated changes in blood insulin and glucagon levels exerting the protective action on the liver and the endocrine pancreas. Our results indicate that the ameliorative potential of resveratrol on metabolic disturbances is due, at least in part, to the direct effects on pancreatic islets and the resulting changes in blood insulin and glucagon levels. It should be also noted that, compared with other studies, advantageous effects of resveratrol were observed already at low dose of this compound. Moreover, it was demonstrated that resveratrol did not induce any significant changes in rats that were not treated with ethanol. Results of the current study, in parallel with the previous data (Ajmo et al. 2008), show that resveratrol holds great potential to prevent and treat hormonal and metabolic disturbances induced by ethanol. It should be, however, mentioned that beneficial effects of resveratrol were shown in rats receiving $10 \mathrm{mg}$ of this compound per $\mathrm{kg}$ body weight and drinking $10 \%$ ethanol solution for two weeks. This is important since resveratrol action may differ depending on its doses and other experimental conditions. Therefore, further studies are required to verify its potential therapeutic value.

\section{Conflict of Interest}

There is no conflict of interest.

\section{Acknowledgements}

This study was supported by Poznan University of Life Sciences research project no: 508-558-02.

\section{References}

AJMO JM, LIANG X, ROGERS CQ, PENNOCK B, YOU M: Resveratrol alleviates alcoholic fatty liver in mice. Am J Physiol Gastrointest Liver Physiol 295: G833-G842, 2008.

BASTIANETTO S, MÉNARD C, QUIRION R: Neuroprotective action of resveratrol. Biochim Biophys Acta 1852: 1195-1201, 2015.

BAUR JA, PEARSON KJ, PRICE NL, JAMIESON HA, LERIN C, KALRA A, PRABHU VV, ALLARD JS, LOPEZLLUCH G, LEWIS K, ET AL.: Resveratrol improves health and survival of mice on a high-calorie diet. Nature 444: 337-342, 2006.

BHULLAR KS, HUBBARD BP: Lifespan and healthspan extension by resveratrol. Biochim Biophys Acta 1852: 1209-1218, 2015. 
BISHAYEE A, DARVESH AS, POLITIS T, MCGORY R: Resveratrol and liver disease: from bench to bedside and community. Liver Int 30: 1103-1114, 2010.

BREEN DM, SANLI T, GIACCA A, TSIANI E: Stimulation of muscle cell glucose uptake by resveratrol through sirtuins and AMPK. Biochem Biophys Res Commun 374: 117-122, 2008.

CENI E, MELlO T, GALLI A: Pathogenesis of alcoholic liver disease: role of oxidative metabolism. World J Gastroenterol 20: 17756-17772, 2014.

DAS SK, MUKHERJEE S, GUPTA G, RAO DN, VASUDEVAN DM: Protective effect of resveratrol and vitamin $\mathrm{E}$ against ethanol-induced oxidative damage in mice: biochemical and immunological basis. Ind J Biochem Biophys 47: 32-37, 2010.

DE LIGT M, TIMMERS S, SCHRAUWEN P: Resveratrol and obesity: Can resveratrol relieve metabolic disturbances? Biochim Biophys Acta 1852: 1137-1144, 2015.

DENG JY, HSIEH PS, HUANG JP, LU LS, HUNG LM: Activation of estrogen receptor is crucial for resveratrolstimulating muscular glucose uptake via both insulin-dependent and -independent pathways. Diabetes 57: 1814-1823, 2008.

FARGHALI H, KUTINOVÁ CANOVÁ N, LEKIĆ N: Resveratrol and related compounds as antioxidants with an allosteric mechanism of action in epigenetic drug targets. Physiol Res 62: 1-13, 2013.

FERNANDEZ-SOLÀ J, PREEDY VR, LANG CH, GONZALEZ-REIMERS E, ARNO M, LIN JC, WISEMAN H, ZHOU S, EMERY PW, NAKAHARA T, ET AL.: Molecular and cellular events in alcohol-induced muscle disease. Alc Clin Exp Res 31: 1953-1962, 2007.

GARCÍA-VILLAFRANCA J, GUILLÉN A, CASTRO J: Ethanol consumption impairs regulation of fatty acid metabolism by decreasing the activity of AMP-activated protein kinase in rat liver. Biochimie 90: 460-466, 2008.

HARDIE DG: AMPK: positive and negative regulation, and its role in whole-body energy homeostasis. Curr Opp Cell Biol 33: 1-7, 2015.

JIANG XS, ZHOU H, ZHANG L, SHENG QH, LI SJ, LI L, HAO P, LI YX, XIA QC, WU JR, ZENG R: A highthroughput approach for subcellular proteome: identification of rat liver proteins using subcellular fractionation coupled with two-dimensional liquid chromatography tandem mass spectrometry and bioinformatic analysis. Mol Cell Prot 3: 441-455, 2004.

JIANG Z, ZHOU J, ZHOU D, ZHU Z, SUN L, NANJI AA: The adiponectin-SIRT1-AMPK pathway in alcoholic fatty liver disease in the rat. Alc Clin Exp Res 39: 424-433, 2015.

KASDALLAH-GRISSA A, MORNAGUI B, AOUANI E, HAMMAMI M, EL MAY M, GHARBI N, KAMOUN A, EL-FAZAÂ S: Resveratrol, a red wine polyphenol, attenuates ethanol-induced oxidative stress in rat liver. Life Sci 80: 1033-1039, 2007.

KASDALLAH-GRISSA A, MORNAGUI B, AOUANI E, HAMMAMI M, GHARBI N, KAMOUN A, EL-FAZAA S: Protective effect of resveratrol on ethanol-induced lipid peroxidation in rats. Alc Alc 41: 236-239, 2006.

KAWARATANI H, TSUJIMOTO T, DOUHARA A, TAKAYA H, MORIYA K, NAMISAKI T, NOGUCHI R, YOSHIJI H, FUJIMOTO M, FUKUI H: The effect of inflammatory cytokines in alcoholic liver disease. Med Inflamm 2013: 495156, 2013.

KOKO V, TODOROVIĆ V, NIKOLIĆ JA, GLISIĆ R, CAKIĆ M, LACKOVIĆ V, PETRONIJEVIĆ L, STOJKOVIĆ M, VARAGIĆ J, JANIĆ B: Rat pancreatic B-cells after chronic alcohol feeding. A morphometric and fine structural study. Histol Histopathol 10: 325-337, 1995.

KONG W, CHEN LL, ZHENG J, ZHANG HH, HU X, ZENG TS, HU D: Resveratrol supplementation restores high-fat diet-induced insulin secretion dysfunction by increasing mitochondrial function in islet. Exp Biol Med (Maywood) 240: 220-229, 2015.

KOPP P: Resveratrol, a phytoestrogen found in red wine. A possible explanation for the conundrum of the 'French paradox'? Eur J Endocrinol 138: 619-620, 1998.

KULKARNI SS, CANTÓ C: The molecular targets of resveratrol. Biochim Biophys Acta 1852: 1114-1123, 2015.

LEE BH, LEE CC, CHENG YH, CHANG WC, HSU WH, WU SC: Graptopetalum paraguayense and resveratrol ameliorates carboxymethyllysine (CML)-induced pancreas dysfunction and hyperglycemia. Food Chem Toxicol 62: 492-498, 2013. 
LEE YE, KIM JW, LEE EM, AHN YB, SONG KH, YOON KH, KIM HW, PARK CW, LI G, LIU Z, KO SH: Chronic resveratrol treatment protects pancreatic islets against oxidative stress in $\mathrm{db} / \mathrm{db}$ mice. PLoS One 7: 50412, 2012.

LUO J: Autophagy and ethanol neurotoxicity. Autophagy 10: 2099-20108, 2014.

OLIVA J, FRENCH BA, LI J, BARDAG-GORCE F, FU P, FRENCH SW: Sirt1 is involved in energy metabolism: the role of chronic ethanol feeding and resveratrol. Exp Mol Pathol 85: 155-159, 2008.

PALSAMY P, SUBRAMANIAN S: Ameliorative potential of resveratrol on proinflammatory cytokines, hyperglycemia mediated oxidative stress, and pancreatic beta-cell dysfunction in streptozotocin-nicotinamideinduced diabetic rats. $J$ Cell Physiol 224: 423-32, 2010.

POULSEN MM, FJELDBORG K, ORNSTRUP MJ, KJÆR TN, NØHR MK, PEDERSEN SB: Resveratrol and inflammation: Challenges in translating pre-clinical findings to improved patient outcomes. Biochim Biophys Acta 1852: 1124-1136, 2015.

PRAVDOVA E, MACHO L, FICKOVA M: Alcohol intake modifies leptin, adiponectin and resistin serum levels and their mRNA expressions in adipose tissue of rats. Endocrine Regul 43: 117-125, 2009.

RADEK KA, RANZER MJ, DIPIETRO LA: Brewing complications: the effect of acute ethanol exposure on wound healing. J Leuk Biol 86: 1125-1134, 2009.

SETSHEDI M, WANDS JR, MONTE SM: Acetaldehyde adducts in alcoholic liver disease. Oxid Med Cell Long 3: 178-185, 2010.

SINGH CK, NDIAYE MA, AHMAD N: Resveratrol and cancer: Challenges for clinical translation. Biochim Biophys Acta 1852: 1178-1185, 2015.

SINGH SP, PATEL DG, SNYDER AK, PULLEN GL: Ethanol influence on insulin secretion from isolated rat islets. Experientia 15: 58-60, 1986.

SUMIDA KD, COGGER AA, MATVEYENKO AV: Alcohol-induced suppression of gluconeogenesis is greater in ethanol fed female rat hepatocytes than males. Alcohol 41: 67-75, 2007.

SUN AY, INGELMAN-SUNDBERG M, NEVE E, MATSUMOTO H, NISHITANI Y, MINOWA Y, FUKUI Y, BAILEY SM, PATEL VB, CUNNINGHAM CC, ET AL.: Ethanol and oxidative stress. Alcohol Clin Exp Res 25 (5 Suppl ISBRA): 237S-243S, 2001.

SUN K, REN M, LIU D, WANG C, YANG C, YAN L: Alcohol consumption and risk of metabolic syndrome: a meta-analysis of prospective studies. Clin Nutr 33: 596-602, 2014.

SZKUDELSKA K, NOGOWSKI L, NOWICKA E, SZKUDELSKI T: In vivo metabolic effects of naringenin in the ethanol consuming rat and the effect of naringenin on adipocytes in vitro. J Anim Physiol Anim Nutr (Berl) 91: 91-99, 2007.

SZKUDELSKA K, NOGOWSKI L, SZKUDELSKI T: Resveratrol, a naturally occurring diphenolic compound, affects lipogenesis, lipolysis and the antilipolytic action of insulin in isolated rat adipocytes. J Ster Biochem Mol Biol 113: 17-24, 2009.

SZKUDELSKA K, SZKUDELSKI T: Resveratrol, obesity and diabetes. Eur J Pharmacol 635: 1-8, 2010.

SZKUDELSKI T: Phytic acid-induced metabolic changes in the rat. J Anim Physiol Anim Nutr (Berl) 89: 397-402, 2005.

SZKUDELSKI T, BIALIK I, SZKUDELSKA K: Adipocyte lipolysis, hormonal and metabolic changes in ethanoldrinking rats. J Anim Physiol Anim Nutr (Berl) 88: 251-258, 2004.

SZKUDELSKI T, KANDULSKA K: The effect of myo-inositol on ethanol-induced metabolic changes and insulin concentration in the rat. Arch Physiol Biochem 107: 334-337, 1999.

SZKUDELSKI T, SZKUDELSKA K: Resveratrol and diabetes: from animal to human studies. Biochim Biophys Acta 1852: $1145-1154,2015$.

TONG M, LONGATO L, RAMIREZ T, ZABALA V, WANDS JR, DE LA MONTE SM: Therapeutic reversal of chronic alcohol-related steatohepatitis with the ceramide inhibitor myriocin. Int J Exp Pathol 95: 49-63, 2014.

ZHANG J, CHEN L, ZHENG J, ZENG T, LI H, XIAO H, DENG X, HU X: The protective effect of resveratrol on islet insulin secretion and morphology in mice on a high-fat diet. Diab Res Clin Pract 97: 474-482, 2012. 
ZHAO LN, HAO LP, YANG XF, YING CJ, YU D, SUN XF: The diabetogenic effects of excessive ethanol: reducing beta-cell mass, decreasing phosphatidylinositol 3-kinase activity and GLUT-4 expression in rats. $\mathrm{Br} J \mathrm{Nutr}$ 101: 1467-1473, 2009.

ZORDOKY BN, ROBERTSON IM, DYCK JR: Preclinical and clinical evidence for the role of resveratrol in the treatment of cardiovascular diseases. Biochim Biophys Acta 1852: 1155-1177, 2015. 